\title{
Effects of Astragaloside IV on heart failure in rats
}

\author{
Zhuanyou Zhao*1, Weiting Wang1, Fang Wang2, Kerui Zhao ${ }^{3}$, Yingmei Han'1, \\ Weiren $\mathrm{Xu}^{1}$ and Lida Tang*1
}

\author{
Address: ${ }^{1}$ State Key Laboratory of Pharmacokinetics and Pharmacodynamics, Tianjin Institute of Pharmaceutical Research, Tianjin 300193, PR \\ China, ${ }^{2}$ Department of Pharmacology, Tongji Medical College, Huazhong University of Science and Technology, Wuhan 430030, PR China and \\ ${ }^{3}$ Department of Pharmacy, Tianjin Medical College, Tianjin 300222, PR China \\ Email: Zhuanyou Zhao* - 23006858@163.com; Weiting Wang - wangweiting2000@163.com; Fang Wang -wangfang0322@yahoo.com.cn; \\ Kerui Zhao - kerui@tjutcm.edu.cn; Yingmei Han - Yingmei-tcmch405@163.com; Weiren Xu - Weiren-xwrtj@yahoo.com.cn; \\ Lida Tang* - tangld@163.net \\ * Corresponding authors
}

Published: 2 April 2009

Chinese Medicine 2009, 4:6 doi:10.1186/1749-8546-4-6

This article is available from: http://www.cmjournal.org/content/4/I/6

This is an Open Access article distributed under the terms of the Creative Commons Attribution License (http://creativecommons.org/licenses/by/2.0), which permits unrestricted use, distribution, and reproduction in any medium, provided the original work is properly cited.

\begin{abstract}
Background: Astragaloside IV (ASI) in Radix Astragali is believed to be the active component in treating heart failure. The present study aims to examine the effects of ASI on cardiovascular parameters in long-term heart failure in rats.

Methods: Using echocardiographic and haemodynamic measurements, we studied the effects of ASI on congestive heart failure (CHF) induced by ligation of the left coronary artery in rats.

Results: ASI (0.1, 0.3 and $1.0 \mathrm{mg} / \mathrm{kg} /$ day) attenuated the decline of fractional shortening (FS). The peak derivatives of the left ventricle (LV) pressure $(\mathrm{dp} / \mathrm{dt})$ in ASI-treated groups significantly increased. Both LV internal diameters in diastole (LVIDd) and in systole (LVIDs) decreased significantly after ASI treatment $(0.3$ and $1.0 \mathrm{mg} / \mathrm{kg} / \mathrm{day})$. ASI $(1.0 \mathrm{mg} / \mathrm{kg} /$ day $)$ attenuated the decrease of LV systolic pressure (LVSP). ASI treatment inhibited compensatory hypertrophy of myocardial cells and lowered the number of apoptotic myocytes.
\end{abstract}

Conclusion: ASI improved cardiac functions as measured by cardiovascular parameters.

\section{Background}

Heart failure is a major cause of morbidity and mortality around the world and remains a serious outcome of myocardial infarction (MI). Radix Astragali (Huangqi) is a Chinese herbal medicine reported to improve the left ventricular function and mitigating the cardiac hypertrophy in heart failure patients [1-5]. Recently, increasing evidence shows that Astragaloside IV (ASI), which is a saponin, is the active ingredient in the treatment of heart failure [6-10]. ASI increased systolic and diastolic functions in acute heart failure of canine induced by pentobarbital sodium and improved the cardiac depressant effect induced by propanolol. Another study [11] further demonstrated a protective effect on the left ventricular modelling and ejection function in patients with congestive heart failure (CHF) after a two-week continuous administration of ASI. Furthermore, the antiapoptotic activities of ASI were discovered in some diseases such as myocarditis [12].

Recent studies showed that cardiac hypertrophy and apoptosis were correlated with the severity of CHF $[13,14]$. Cardiocyte apoptosis plays an important role in the remodelling process and in the transition from adap- 
tive myocardial condition to end-stage cardiac failure. Cardiac apoptosis is a genetically programmed process executed by caspases, a family of ubiquitous cysteine proteases. Caspases are present in the cell as inactive pro-caspases, which are activated in response to apoptotic stimuli including myocardial pathological conditions (e.g. hypoxia, oxidation, and mechanical load), cytokines (e.g. TNF- $\alpha$, IL- 6 and ITF) and neuroendocrine factors (e.g. angiotensin II and NO) [15]. Gene families Bcl-2 and P53 also take part in the regulation of apoptosis [16]. However, the effects of ASI on heart failure have not been extensively elucidated.

The present study aims to examine the effects of ASI on cardiovascular parameters in long-term heart failure as an outcome of MI in rats.

\section{Methods}

\section{Animals and reagents}

Wistar rats weighting $228.3 \pm 13.0 \mathrm{~g}(203-272 \mathrm{~g})$ were housed at $22 \pm 2{ }^{\circ} \mathrm{C}$ in a temperature-regulated room equipped with an automatic 12:12 hour photoperiod and were provided with food and water. ASI is colourless needles crystallized from Astragaloside by ethyl acetate-ethanol, melting point $295-300^{\circ} \mathrm{C}$, purity $>95 \%$. ASI was dissolved in $20 \%$ dimethylsulfoxide $(<0.05 \%)$ and diluted with normal saline (NS) when studied in vivo. Quinapril was supplied by the Shanghai Institute of Pharmaceutical Industry (certificate no.051).

\section{Induction of $\mathrm{MI}$ and medications}

MI in Wistar rats was induced by coronary ligation. Through a thoracotomy on the left side, the heart was exteriorized and extensive MI was induced by ligation of the left coronary artery according to Tonnessen $e t$ al. [17]. Animals in the sham group were subjected to the same surgical procedure, except that the coronary artery was not ligated. Echocardiography was performed three weeks later in the surviving rats anaesthetized by ether; those with heart failure according to echocardiographic criteria were randomly divided into five groups $[18,19]$ where each group had ten animals. Group one (model) received NS; group two to four received ASI at $0.1,0.5,1.0 \mathrm{mg} / \mathrm{kg}$ respectively; group five received quinapril at $1.0 \mathrm{mg} / \mathrm{kg}$. The animals in the sham group received NS. The treatment, which started three weeks after coronary ligation, was carried out via intravenous injection once a day for 14 days. The experiment lasted for five weeks.

\section{Echocardiography}

We used a commercially available echocardiography (VIVID 3 Pro, GE, USA) equipped with a $10 \mathrm{MHz}$ linear transducer. The animals, with shaved chests, were placed in supine position. The transducer was placed gently on the left. Two-dimensional (2D) images of the left ventricle
(LV) were obtained in both parasternal long-axis and short-axis views at a frame rate of $130 \mathrm{~Hz}$. M-mode tracings were recorded at the level of the papillary muscles with $2 \mathrm{D}$ guidance. $\mathrm{LV}$ wall thickness and cavity diameters were measured outside the infarcted area by M-mode, through the largest diameters of the ventricle. Each image consisted of 24 consecutive heart cycles and the focus area was $0-40 \mathrm{~mm}$ from the transducer. Fractional shortening (FS), in percentage, was calculated according to the following formula:

$$
\mathrm{FS}=[(\text { LVIDd }- \text { LVIDs }) / \text { LVIDd }] \times 100 \%
$$

where LVIDd is the LV internal diameter in diastole, and LVIDs is the LV internal diameter in systole [20]. LV internal diameters were measured according to the guidelines of the American Society of Echocardiography [21]. All measurements were obtained on at least three beats. LV systolic wall stress $=1.36 \times$ (aortic systolic pressure $\times$ LVIDs)/(IVSs + LVPWs), where IVSs is the interventricular septum thickness at end-systole and LVPWs is the posterior wall thickness at end-systole. The tracings were analyzed by one author (WTW) who had no prior knowledge of the group assignment.

\section{Haemodynamic measurements}

An F-2 (0.7 mm in internal diameter) catheter with pressure-transducer was inserted through the right carotid artery into the aorta to determine the mean arterial blood pressure. The catheter was subsequently advanced further into the LV, and end-diastolic pressure (LVEDP) and systolic pressure (LVSP) were recorded. The transducer was connected to a polygraph (model 6300, Nihon Kohden, Japan) and a data acquisition workstation (model MP150, BIOPAC Systems, USA) to a computer running Acknowledge (version 3.7.1). LVEDP was read directly from the pressure curve as being the diastolic pressure immediately preceding the pressure rise associated with LV contraction. Peak positive and peak negative first derivatives of the $\mathrm{LV}$ pressure $(+\mathrm{LVdp} / \mathrm{dt}$ and $-\mathrm{LVdp} / \mathrm{dt})$ were calculated with the Acknowledge software.

\section{Tissue sampling}

After haemodynamic measurements, the rats were subsequently euthanized by excision of the heart. The atria and ventricles were sectioned, separated and weighted. The infarcted area (scar tissue) was excised with care from the non-infarcted LV to avoid contamination of viable myocardial tissue by necrotic tissue. The infarction size was estimated by weighing the excised scar tissue. The non-infarcted LV from the CHF rats was further sectioned by separating the tissue contiguous to the infarcted area (viable LV free wall) and the tissue distal to the infarcted area (interventricular septum). A piece of the apical part of the nonischemic interventricular septum was processed sepa- 
rately for histochemical analysis of apoptosis. The right tibia of each rat was isolated and its length measured [22]. Myocardial tissue from interventricular septum was microtomed into $5 \mu \mathrm{m}$ sections. Apoptotic cell death was analyzed by terminal-deoxynucleotidyl transferase (TdT)mediated dUTP-digoxigenin nick end labelling (TUNEL) method. The Bcl-2 associated X protein (Bax) related to apoptosis was determined with biotin SP-HRP.

\section{Statistical analysis}

Data are expressed as mean \pm standard deviation (SD). The statistical significance between groups was evaluated by a one-way analysis of variance (ANOVA) with SAS software (version 10.0, SAS Institute, USA). $P$ values $<0.05$ are considered to be statistically significant.

\section{Results Effects of ASI on the LV functions}

Three weeks after coronary artery ligation, the FS of the animals in the model group markedly decreased and further decreased after the animals were given NS for two more weeks. The values of $+\mathrm{dp} / \mathrm{dt}$ and $-\mathrm{dp} / \mathrm{dt}$ decreased $36 \%$ and $48 \%$ respectively two weeks after NS administration. One week after the administration of ASI $(0.1,0.3$ and $1.0 \mathrm{mg} / \mathrm{kg} /$ day), the decline of the FS was attenuated $(P<0.05, P<0.001$ and $P<-0.001)$. Two weeks after the administration of ASI (at a dose of $1.0 \mathrm{mg} / \mathrm{kg} /$ day), the decline of the FS was attenuated $(P<0.05)$. The $\mathrm{dp} / \mathrm{dt}$ in the ASI-treated groups ( 0.3 and $1.0 \mathrm{mg} / \mathrm{kg} /$ day $)$ significantly increased compared with the model group $(P<$ 0.05 and $P<0.01$ ) (Tables 1 and 2).

\section{Effects of ASI on LV dimensions}

LV geometry in various groups was analyzed with echocardiography (Table 3 ). The findings demonstrated the progression of LV remodelling during a 5-week period after coronary artery ligation in the absence of treatment. Both LVIDd and LVIDs increased significantly and progressively three weeks after surgery. Both LVIDd and LVIDs decreased significantly two weeks after ASI treatment $(0.3$ and $1.0 \mathrm{mg} / \mathrm{kg} /$ day).

\section{Effects of ASI on haemodynamics}

LVSP in the model group was $21 \%$ lower than that in the sham group, while LVEDP in the model group increased markedly, suggesting severe cardiac dysfunction in the CHF rats after coronary artery ligation (Table 4). ASI (at doses of 0.1 and $0.3 \mathrm{mg} / \mathrm{kg} /$ day) attenuated the decrease of LVSP, while LVEDP decreased 55.4\% $(P<0.01)$ compared with the model group. The rats in the model group displayed higher wall stress of LV. ASI $(1.0 \mathrm{mg} / \mathrm{kg} /$ day $)$ significantly lowered the wall stress by $22 \%(P<0.05)$ compared with the model group.

\section{Effects of ASI on myocardial hypertrophy}

LA, LV, RA and RV weight-to-tibial-length ratios decreased significantly after ASI $(1.0 \mathrm{mg} / \mathrm{kg} /$ day $)$ treatment compared with the model group (Table 5).

\section{Effects of ASI on myocardial apoptosis and Bax}

Assessment of apoptotic cell death was performed with in situ TUNEL staining of mycardial sections. Apoptosis was observed in the CHF rats with an increased level of Bax protein. Compared with the model group, both apoptotic cells and Bax proteins were reduced markedly after two weeks of ASI treatment $(1.0 \mathrm{mg} / \mathrm{kg} /$ day) (Table 6$)$.

\section{Discussion}

$\mathrm{CHF}$ is a serious outcome of MI. Many rats may die from serious ischemia after induction of acute MI by coronary artery ligation. However, rats suffering from slight ischemia may develop CHF. In the present study, surgery was performed on 141 rats, among which 48 rats died within 24 hours (34\% mortality rate) and 61 rats developed CHF according to echocardiographic criteria for $\mathrm{CHF}$ [22]. The rats were dissected for the scar tissue at the end of experiments. Rats with coronary artery ligation had moderate infarcted area of $2.67 \pm 0.39(2.08-3.52) \mathrm{mg} /$ $\mathrm{mm}$. Rats in the sham group had no infarcted area.

Routinely used on humans, echocardiography is emerging as a noninvasive method for evaluating global systolic cardiac function and LV dimensions in rats [23-27]. In the

Table I: Effects of ASI on FS (\%)

\begin{tabular}{|c|c|c|c|c|c|}
\hline Group & Dose (mg/kg/day) & Normal & Before treatment & $\begin{array}{l}\text { After treatment } \\
\text { I week }\end{array}$ & 2 weeks \\
\hline Sham & - & $73.0 \pm 5.7$ & $68.8 \pm 6.5$ & $70.9 \pm 3.4$ & $66.1 \pm 8.0$ \\
\hline Model & - & $68.8 \pm 10.1(0.2193)$ & $30.8 \pm 5.0^{+++}$ & $26.1 \pm 6.6^{+++}$ & $22.7 \pm 7.6^{+++}$ \\
\hline ASI & 0.1 & $72.8 \pm 3.6(0.2417)$ & $28.9 \pm 4.6(0.4213)$ & $34.2 \pm 7.5^{*}(0.0163)$ & $27.4 \pm 7.8(0.2620)$ \\
\hline ASI & 0.3 & $72.1 \pm 9.6(0.3329)$ & $28.8 \pm 6.9(0.3973)$ & $41.5 \pm 11.3^{* * *}$ & $28.8 \pm 8.9(0.1474)$ \\
\hline ASI & 1.0 & $68.4 \pm 6.7(0.9061)$ & $31.7 \pm 2.5(0.7024)$ & $42.9 \pm 7.7^{* * *}$ & $35.8 \pm 13.2^{* *}(0.0028)$ \\
\hline Quinapril & 1.0 & $70.1 \pm 7.5(0.7016)$ & $30.2 \pm 4.7(0.7989)$ & $42.4 \pm 4.7^{* * *}$ & $31.4 \pm 8.8^{*}(0.04 I I)$ \\
\hline
\end{tabular}

Note: Values are mean $\pm S D$ in each group $(n=10) .{ }^{+++} P<0.001$ : statistical significance over the sham group (comparison of group means after ANOVA). $* P<0.05$, $* * P<0.01$, $* * * P<0.001$ : statistical significances over the model group (comparison of group means after ANOVA). No statistical significance between ASI $(1.0 \mathrm{mg} / \mathrm{kg} /$ day $)$ and Quinapril treatments. Exact $P$ values are available in brackets. 
Table 2: Effects of ASI on +dp/dt and -dp/dt

\begin{tabular}{llll}
\hline Group & Dose $(\mathrm{mg} / \mathrm{kg} / \mathrm{day})$ & $+\mathrm{dp} / \mathrm{dt}(\mathrm{mmHg} / \mathrm{s})$ & $-\mathrm{dp} / \mathrm{dt}(\mathrm{mmHg} / \mathrm{s})$ \\
\hline Sham & - & $3454 \pm 774$ & $3706 \pm 517$ \\
Model & - & $2216 \pm 800^{+++}$ & $1922 \pm 672^{+++}$ \\
ASI & 0.1 & $2459 \pm 524(0.3679)$ & $2362 \pm 610(0.0710)$ \\
ASI & 0.3 & $2838 \pm 420^{*}(0.0246)$ & $2699 \pm 425 * *(0.0021)$ \\
ASI & 1.0 & $3066 \pm 630^{* *}(0.0027)$ & $2776 \pm 578^{* * * *}$ \\
Quinapril & 1.0 & $2847 \pm 25 I^{*}(0.0228)$ & $2601 \pm 310^{* * *}(0.0065)$ \\
\hline
\end{tabular}

Note: Values are mean \pm SD in each group $(n=10) .{ }^{++} P<0.00 \mathrm{I}$ : statistical significance over the sham group (comparison of group means after ANOVA). $* P<0.05, * * P<0.01, * * * P<0.001$ : statistical significance over the model group (comparison of group means after ANOVA). No significance between ASI $(1.0 \mathrm{mg} / \mathrm{kg} /$ day $)$ and Quinapril treatments. Exact $P$ values are available in brackets.

present study, FS decreased $55.2 \%$ over baseline $(P<$ $0.001)$; LVIDd and LVIDs increased markedly from $4.8 \pm$ $1.2 \mathrm{~mm}$ and $1.5 \pm 0.5$ to $7.0 \pm 1.1 \mathrm{~mm}$ and $4.8 \pm 1.0 \mathrm{~mm}$ respectively $(P<0.001)$. These results are consistent with the findings by Oie et al. [22].

The mechanism of heart failure remains mostly unclear. The loss of cardiomyocytes may play an important role in causing heart failure [28]. Apoptosis is an important source for cardiomyocyte loss. There were 38.92 apoptotic cells per million myocardial cells in rats with heart failure, whereas the rate was only 2.21 cells per million myocardial cells in healthy rats [29].

A previous study showed that quinapril significantly suppressed the incidence of apoptotic myocytes around the necrotic region [30]. In the present study, quinapril significantly suppressed the incidence of apoptotic myocytes in the CHF rats. It was demonstrated that cardiomyocyte apoptosis and various genes associated with apoptosis were inhibited in mice with myocarditis after Astragaloside treatment [12]. In the present study, apoptotic myo- cytes significantly decreased in the CHF rats treated with ASI in a dose-dependent manner.

\section{Conclusion}

The present study showed that ASI improved cardiac functions, inhibited compensatory hypertrophy of myocardial cells and lowered the number of apoptotic myocytes.

\section{Abbreviations}

ASI: Astragaloside IV; Bax: $\mathrm{Bcl}-2$ associated $\mathrm{X}$ protein; CHF: congestive heart failure; FS: fractional shortening; IVSs: interventricular septum thickness at end-systole; LA: left atrium; LV: left ventricle; LVIDd: left ventricle internal diameter in diastole; LVIDs: left ventricle internal diameter in systole; LVEDP: left ventricle end-diastolic pressure; -LVPWs: posterior wall thickness at end-systole; -LVSP: left ventricle systolic pressure; -MI: myocardial infarction; RA: right atrium; RV: right ventricle; $\mathrm{SD}$ : standard deviation; TL: tibial length; wt: weight.

\section{Competing interests}

The authors declare that they have no competing interests.

Table 3: Effects of ASI on LV dimensions

\begin{tabular}{|c|c|c|c|c|c|c|}
\hline & \multirow[b]{2}{*}{ Group } & \multirow[b]{2}{*}{ Dose (mg/kg/day) } & \multirow[b]{2}{*}{ Normal } & \multirow[b]{2}{*}{ Before treatment } & \multicolumn{2}{|c|}{ After treatment } \\
\hline & & & & & I week & 2 weeks \\
\hline & Sham & - & $4.8 \pm 1.0$ & $5.2 \pm 1.3$ & $5.2 \pm 0.7$ & $5.2 \pm 0.9$ \\
\hline & Model & - & $4.8 \pm 1.2(0.9549)$ & $7.0 \pm 1.1^{++}(0.0046)$ & $7.5 \pm 0.4^{+++}$ & $7.1 \pm 0.7^{+++}$ \\
\hline \multirow[t]{6}{*}{ LVIDd (mm) } & ASI & 0.1 & $5.0 \pm 0.8(0.6785)$ & $6.9 \pm 1.2(0.9603)$ & $6.9 \pm 1.0(0.1601)$ & $6.5 \pm 1.1(0.1109)$ \\
\hline & ASI & 0.3 & $4.5 \pm 1.2(0.5850)$ & $6.2 \pm 1.9(0.1946)$ & $6.7 \pm 1.7(0.0547)$ & $6.0 \pm 0.9 * *(0.0057)$ \\
\hline & ASI & 1.0 & $4.7 \pm I .5(0.7629)$ & $6.4 \pm 1.3(0.3389)$ & $6.5 \pm 0.8 *(0.0193)$ & $6.0 \pm 0.5^{*} * \$(0.0046)$ \\
\hline & Quinapril & 1.0 & $5.1 \pm 1.2(0.6512)$ & $6.6 \pm 1.1(0.5964)$ & $6.7 \pm 0.8(0.0574)$ & $6.7 \pm 0.9(0.3837)$ \\
\hline & Sham & - & $1.3 \pm 0.4$ & $1.6 \pm 0.4$ & $1.5 \pm 0.3$ & $1.8 \pm 0.5$ \\
\hline & Model & - & $1.5 \pm 0.5(0.4268)$ & $4.8 \pm 1^{+++}$ & $5.6 \pm 0.8^{+++}$ & $5.5 \pm 0.8^{+++}$ \\
\hline \multirow[t]{4}{*}{ LVIDs (mm) } & ASI & 0.1 & $1.4 \pm 0.3(0.88 \mid \mathrm{I})$ & $4.9 \pm 0.9(0.8356)$ & $4.5 \pm 0.9 *(0.0112)$ & $4.7 \pm 0.9 *(0.0447)$ \\
\hline & ASI & 0.3 & $1.2 \pm 0.4(0.1827)$ & $4.5 \pm 1.6(0.3955)$ & $4.0 \pm 1.6^{* * *}$ & $4.3 \pm 1.0 * *(0.0027)$ \\
\hline & ASI & 1.0 & $1.4 \pm 0.4(0.6903)$ & $4.4 \pm 0.8(0.3353)$ & $3.7 \pm 0.7^{* * * *}$ & $3.8 \pm 1.0 * * * \$$ \\
\hline & Quinapril & 1.0 & $1.6 \pm 0.7(0.5180)$ & $4.6 \pm 0.7(0.6125)$ & $3.9 \pm 0.6^{* * *}$ & $4.8 \pm 0.8(0.0595)$ \\
\hline
\end{tabular}

Note: Values are mean $\pm S D$ in each group $(n=10) .{ }^{++} p<0.01,{ }^{+++} p<0.001$ : statistical significance over the sham group (comparison of group means after ANOVA). $* P<0.05, * * P<0.01$, $* * * P<0.001$ : statistical significance over the model group (comparison of group means after ANOVA). $\$ P<0.05$ : statistical significance between ASI $(1.0 \mathrm{mg} / \mathrm{kg} /$ day) and Quinapril treatments (comparison of group means after ANOVA). Exact $P$ values are available in brackets. 
Table 4: Effects of ASI on LVSP, LVEDP and wall stress

\begin{tabular}{lllll}
\hline Group & Dose $(\mathrm{mg} / \mathrm{kg} / \mathrm{day})$ & LVSP $(\mathrm{mmHg})$ & LVEDP $(\mathrm{mmHg})$ & Wall stress $\left(\mathrm{g} / \mathrm{cm}^{2}\right)$ \\
\hline Sham & - & $111.8 \pm 12.1$ & $-0.7 \pm 5.8$ & $47.7 \pm 17.6$ \\
Model & - & $88.5 \pm 14.0^{+++}$ & $13.9 \pm 5.4^{+++}$ & $125.9 \pm 28.0^{+++}$ \\
ASI & 0.1 & $101.4 \pm 18.5^{*}(0.0367)$ & $10.6 \pm 3.6(0.1629)$ & $120.4 \pm 31.9(0.6563)$ \\
ASI & 0.3 & $101.6 \pm 9.0^{*}(0.0340)$ & $9.8 \pm 5.3(0.0848)$ & $108.3 \pm 24.5(0.1613)$ \\
ASI & 1.0 & $100.2 \pm 8.4 \$(0.0571)$ & $6.2 \pm 4.2^{* *}(0.0018)$ & $97.9 \pm 29.8^{*}(0.0283)$ \\
Quinapril & 1.0 & $84.0 \pm 15.5(0.4566)$ & $3.5 \pm 6.3^{* * *}$ & $95.1 \pm 31.7^{*}(0.0167)$ \\
\hline
\end{tabular}

Note: Values are mean \pm SD in each group $(n=10) .^{+++} p<0.001$ : statistical significance over the sham group (comparison of group means after ANOVA). $* P<0.05, * * P<0.01$, $* * * P<0.001$ : statistical significance over the model group (comparison of group means after ANOVA). $\$ \$ P<0.01$ : statistical significance between ASI ( $1.0 \mathrm{mg} / \mathrm{kg} / \mathrm{day}$ ) and Quinapril treatments (comparison of group means after ANOVA). Exact $P$ values are available in brackets.

Table 5: Effects of ASI on myocardial hypertrophy

\begin{tabular}{llllllll}
\hline Group & $\begin{array}{l}\text { Dose } \\
(\mathrm{mg} / \mathrm{kg} / \mathrm{day})\end{array}$ & $\begin{array}{l}\text { LA wt/TL } \\
(\mathrm{mg} / \mathrm{mm})\end{array}$ & $\begin{array}{l}\mathrm{LV} \text { wt/TL } \\
(\mathrm{mg} / \mathrm{mm})\end{array}$ & $\begin{array}{l}\text { RA wt/TL } \\
(\mathrm{mg} / \mathrm{mm})\end{array}$ & $\begin{array}{l}\text { RV wt/TL } \\
(\mathrm{mg} / \mathrm{mm})\end{array}$ & $\begin{array}{l}\text { Tibial length } \\
(\mathrm{mm})\end{array}$ \\
\hline Sham & - & $1.3 \pm 0.6$ & $20.3 \pm 3.1$ & $1.8 \pm 0.6$ & $5.5 \pm 1.5$ & $37.25 \pm 1.23$ & $290.2 \pm 23.2$ \\
Model & - & $2.8 \pm 0.7^{+++}$ & $24.9 \pm 2.1^{+++}$ & $2.6 \pm 0.5^{+++}$ & $8.1 \pm 1.5^{+++}$ & $38.20 \pm 1.70$ & $280.1 \pm 24.3$ \\
& & - & & & & $(0.1879)$ & $(0.3439)$ \\
ASI & 0.1 & $2.4 \pm 0.4$ & $22.7 \pm 2.8$ & $2.5 \pm 0.4$ & $7.1 \pm 1.0$ & $38.96 \pm 1.28$ & $271.2 \pm 18.0$ \\
& & $(0.1855)$ & $(0.0862)$ & $(0.6751)$ & $(0.1031)$ & $(0.2723)$ & $(0.4038)$ \\
ASI & 0.3 & $2.5 \pm 0.7$ & $22.6 \pm 4.0$ & $2.5 \pm 0.5$ & $7.1 \pm 1.2$ & $37.23 \pm 1.36$ & $287.9 \pm 31.6$ \\
& & $(0.2280)$ & $(0.0796)$ & $(0.7632)$ & $(0.099)$ & $(0.1811)$ & $(0.4639)$ \\
ASI & 1.0 & $2.1 \pm 0.6^{*}$ & $21.0 \pm 2.6^{* *}$ & $2.0 \pm 0.7^{*}$ & $6.1 \pm 1.3^{* *}$ & $37.89 \pm 1.28$ & $294.5 \pm 15.7$ \\
& & $(0.015)$ & $(0.0031)$ & $(0.0186)$ & $(0.0017)$ & $(0.6827)$ & $(0.1794)$ \\
Quinapril & 1.0 & $2.0 \pm 0.8^{* *}$ & $22.0 \pm 1.8^{*}$ & $2.0 \pm 0.6^{*}$ & $7.2 \pm 1.8$ & $38.13 \pm 2.27$ & $280.1 \pm 25.6$ \\
& & $(0.0076)$ & $(0.0255)$ & $(0.0223)$ & $(0.1485)$ & $(0.9434)$ & $(1.0)$ \\
\end{tabular}

Note: Values are mean $\pm S D$ in each group $(n=10) .{ }^{++} p<0.001$ : statistical significance over the sham group (comparison of group means after ANOVA). $* P<0.05$, $* * P<0.01$ : statistical significance over the model group (comparison of group means after ANOVA). No statistical significance between ASI ( $1.0 \mathrm{mg} / \mathrm{kg} / \mathrm{day})$ and Quinapril treatments (comparison of group means after ANOVA). Exact $P$ values are available in brackets.

Table 6: Effects of ASI on myocardial apoptosis and Bax

\begin{tabular}{llll}
\hline Group & Dose $(\mathrm{mg} / \mathrm{kg} / \mathrm{day})$ & Apoptotic cell & Bax protein \\
\hline Sham & - & $3.0 \pm 2.2$ & $1.6 \pm 1.3$ \\
Model & - & $54.0 \pm 10.2^{+++}$ & $30.2 \pm 8.8^{+++}$ \\
ASI & 0.1 & $37.8 \pm 8.6^{* * *}$ & $24.3 \pm 7.1^{*}$ \\
ASI & 0.3 & $17.0 \pm 8.4^{* * *}$ & $8.4 \pm 5.3^{* * *}$ \\
ASI & 1.0 & $8.0 \pm 5.6^{* * *}$ & $7.3 \pm 3.4^{* * *}$ \\
Quinapril & 1.0 & $10.4 \pm 6.4^{* * *}$ & $12.0 \pm 5.5^{* * *}$ \\
\hline
\end{tabular}

Note: Values are mean \pm SD in each group $(n=10) .{ }^{++} P<0.001$ : statistical significance over the sham group (comparison of group means after ANOVA). $* P<0.05, * * * P<0.001$ : statistical significance over the model group (comparison of group means after ANOVA). No statistical significance between ASI ( $1.0 \mathrm{mg} / \mathrm{kg} /$ day) and Quinapril treatments (comparison of group means after ANOVA). 


\section{Authors' contributions}

ZYZ, WTW, FW and KRZ drafted the manuscript and performed the experiments. WRX and YMH prepared reagents for the experiments. LDT supervised this work and revised the manuscript. All authors read and approved the final version of the manuscript.

\section{References}

I. Yuan GP: Evaluation of efficacy of Astragalus injection in treatment of patients with chronic heart failure. Zhonguo Linchuang Yaolixue Yu Zhiliaoxue 2003, 8(6):7I0-7II.

2. Zhai LH, Wang M, Yue JM, Ma YZ: The clinical study of Astragalus injection in treatment of patients with chronic heart failure. Shanghai Yiyao Zazhi 1995, II:10-12.

3. Zhu BQ, Dai RH, Gong ZM: Study of the positive effect of astragala injection on heart. Shanghai Zhongyiyao Zazhi 1987, 7(I):47-48.

4. Li SR, Hao JF, Wang Y, Gao XM, Hu LM: Experimental research about the influence of Huangqi injection on hemodynamics in tars with acute heart failure. Tianjin Zhongyiyao 2003, 20(6):56-57.

5. Hong Y, Hui SC, Chan TY, Hou JY: Study of the inhibitory effect of Hangqi injection on experimental cardiac hypertrophy in rats. Zhongchengyao 2002, 24(7):525-529.

6. Wu WP: The experimental study of Astragaloside IV on cardiac effect. Zhongyaocai 2005, 28(7):591-592.

7. Sun CW, Lu WW: Effects of Astragalus saponins on experimental heart failure. Baiqiu'en Yikedaxue Xuebao 1994, 20(2): I25-127.

8. Zheng PL, Dai JY, Chen H, Fu WP, Zhang C, SU J, Chen HZ: Influence of astragaloside IV (ASIV) on systolic and diastolic function in dogs with acute heart failure. Zhongguo Yaolixue Tongbao 2005, 2 I(12): 1534-1535.

9. Liu YX, Liu ZP, Jiao JJ, Lou JS: Effects of Astragaloside IV on myocardial dynamics and cardiac function with normal and depressant cardiac function in rats. Zhongcaoyao 200I, 32(4):332-334.

10. Liu YY, Shen XT: The comparison of cardiac effects of ASI, milrinone, and ouabain on heart failure in guinea pigs. Jichu Yixue Yu Linchuang 200 I, 2 I (6):57 I-572.

II. Luo HM, Dai RH, Li Y, Shi HM, Guan YH, Gong ZM, Liu XJ: Nuclear cardiology study on effective ingredients of austragalus membranaceus in treating heart failure. Zhongguo Zhongxiyi Jiehe Zazhi 1995, I 5( I 2):707-709.

12. Zhang ZC, Li SJ, Yang YZ, Chen RZ, Ge JB, Chen HZ: Effect of astragaloside on cardiomyocyte apoptosis in murine coxsackievirus B3 myocarditis. J Asian Nat Prod Res 2007, 9(2): $|45-5|$

13. Vscovo G, Volterrani M, Zennaro R: Apoptosis in the skeletal muscle of patients with heart failure: investigation of clinical and biochemical changes. Heart 2000, 84:43I-437.

14. Libera LD, Ravara B, Angelini A, Rossini K, Sandri M, Thiene G: Benificial effects on skeletal muscle of the angiotension II type I receptor blocker irbesartan in experimental heart failure. Circulation 200I, I 03:2195-2200.

15. Khoynezhad A, Jalali Z, Tortolani AJ: A Synopsis of Research in Cardiac Apoptosis and Its Application to Congestive Heart Failure. Tex Heart Inst J 2007, 34(3):352-359.

16. Narila J, Haider N, Virmani R: Apoptosis in myocytes in end stage heart failure. N Engl J Med 1996, 335: I I 82-89.

17. Tonnessen T, Christensen G, Oie E, Holt E, Kjekshus H, Smiseth OA, Sejersted OM, Attramadal H: Increased cardiac expression of endothelin-I mRNA in ischemic heart failure in rats. Cardiovasc $\operatorname{Res} 1997,33: 601-610$.

18. Burrell LM, Chan R, Phillips PA: Validation of an echocardiographic assessment of cardiac function following moderate size myocardial infarction in the rat. Clin Exp Pharmacol Physiol 1996, 23(6):570-572.

19. Francis GS: Pathophysiology of chronic heart failure. Am J Med 200I, I I0(SuppI 7A):37-46.

20. Ahmet I, Krawczyk M, Heller P: Beneficial effects of chronic pharmacological manipulation of $\beta$-adrenoreceptor subtype signaling in rodent dilated ischemic cardiomyopathy. Circulation 2004, I 10(9): 1083-1090.

21. Schiller NB, Shah PM, Crawford M, DeMaria A, Devereux R, Feigenbaum H, Gutgesell H, Reichek N, Sahn D, Schnittger I: Recommendations for quantitation of the left ventricle by twodimensional echocardiography. American Society of Echocardiography committee on Standards, Subcommittee on Quantitation of Two-Dimensional Echocardiograms. J Am Soc Echocardiogr 1989, 2:358-367.

22. Oie E, Bjørnerheim R, Clausen OP, Attramadal H: Cyclosporine A inhibits cardiac hypertrophy and enhances cardiac dysfunction during post infarction failure in rats. Am J Physiol Heart Circ Physiol 2000, 278(6): $\mathrm{H} 2$ II 5-23

23. Omerovic E, Bollano E, Basetti M, Kujacic V, Waagstein L, Hjalmarson $A$, Waagstein F, Soussi B: Bioenergetic, functional and morphological consequences of postinfarct cardiac cardiac remodeling in the rat. J Mol Cell Cardiol 1999, 3 I:1685-1695.

24. Sjaastad I, Sejersted OM, llebekk A, Bjornerheim R: Echocardiographic criteria for detection of postinfarction congestive heart failure in rats. J Appl Physiol 2000, 89: I 445- I 454.

25. Yoshiyama M, Takeuchi K, Omura T, Izutani S, Nakamura Y, Akioka $\mathrm{K}$, Kim S, Iwao H, Yoshikawa J: Effect of diltiazem on cardiac remodeling in rats assessed by Doppler echocardiography and mRNA expression. Cardiovasc Drugs Ther 1999, 13:249-258.

26. Hagar JM, Matthews R, Kloner RA: Quantiative two-dimensional echocardiographic assessment of regional wall motion during transient ischemia and reperfusion in the rat. J Am Soc Echocardiogr 1995, 8(2): 162-174.

27. Fabric P, Roger G, Liliane L: Doppler echocardiographic estimation of left ventricular end-diastolic pressure after $\mathrm{MI}$ in rats. Am J Physiol Heart Circ Physiol 2002, 283:H346-H352.

28. Bing $\mathrm{OH}$ : Hypothesis: apoptosis may be a mechanism for the transition to heart failure with chronic pressure overload. J Mol Cell Cardiol 1994, 26:943-948.

29. Li Z, Bing OH, Long X, Robinson KG, Lakatta EG: Increased cardiomyocyte apoptosis during the transition to heart failure in the spontaneously hypertensive rat. Am J Physiol 1997, 272: $\mathrm{H} 23 \mathrm{I} 3-\mathrm{H} 23 \mathrm{I} 9$

30. Kobara M, Tatsumi T, Kambayashi D, Mano A, Yamanaka S, Shiraishi J, Keira N, Matoba S, Asayama J, Fushiki S, Nakagawa M: Effects of ACE inhibition on myocardial apoptosis in an ischemiareperfusion rat heart model. J Cardiovasc Pharmacol 2003, $4 I(6): 880-9$

\section{Publish with BioMed Central and every scientist can read your work free of charge}

"BioMed Central will be the most significant development for disseminating the results of biomedical research in our lifetime."

Sir Paul Nurse, Cancer Research UK

Your research papers will be:

- available free of charge to the entire biomedical community

- peer reviewed and published immediately upon acceptance

- cited in PubMed and archived on PubMed Central

- yours - you keep the copyright 